International Journal of Engineering \& Technology, $7(4.14)(2018) 512-514$
International Journal of Engineering \& Technology
SPC
Website: www.sciencepubco.com/index.php/IJET
Research paper

\title{
Conductivity Performance of Biopolymer Membrane based on Kappa-Carrageenan
}

\author{
Rosnah Zakaria ${ }^{1,2 *}$, Asiah Mohd Nor ${ }^{2}$, Nor Kartini Jaafar ${ }^{2}$, Ab Malik Marwan Ali ${ }^{1,2}$ \\ ${ }^{1}$ Institute of Science, Univerisiti Teknologi MARA, 40450 Shah Alam, Selangor, Malaysia. \\ ${ }^{2}$ Faculty of Applied Sciences, Universiti Teknologi MARA, 40450 Shah Alam, Selangor, Malaysia. \\ *Corresponding author E-mail: rosna593@salam.uitm.edu.my
}

\begin{abstract}
Smart energy systems are well-known among researchers who wish to introduce new technology. Biopolymer is an environmentally friendly material. Kappa-Carrageenan is one type of biopolymer with high proton conductivity and durability which has been studied for almost 10 years. The membrane based on kappa-carrageenan was prepared using solution cast technique incoorperated with ammonium thiocyanate $\left(\mathrm{NH}_{4} \mathrm{SCN}\right)$. The solution was poured into glass petri dishes and left to dry at room temperature before further dying in an oven at $60^{\circ} \mathrm{C}$ to obtain thin films. The highest conductivity was obtained for $40 \mathrm{wt} \% \mathrm{NH}_{4} \mathrm{SCN}$ added kappa-carrageenan. The conductivity dropped when the amount of kappa-carrageenan is equal to the amount of $\mathrm{NH}_{4} \mathrm{SCN}$. The maximum conductivity of kappacarrageenan incorporated with $\mathrm{NH}_{4} \mathrm{SCN}$ obtained is $1.64 \mathrm{E}-03 \mathrm{~S} \mathrm{~cm}^{-1}$. FTIR studies show peak at $1638 \mathrm{~cm}^{-1}$ in pure kappa-carrageenan which slowly disappeared at $60 \mathrm{wt}$. \% kappa-carrageenan. It is however characterized by a peak attributed to $\mathrm{NH}_{4} \mathrm{SCN}$ at $1600 \mathrm{~cm}^{-1}$ which appeared for $50 \mathrm{wt}$ \% of kappa-carrageenan and below.
\end{abstract}

Keywords: Proton Conductivity, EIS, FTIR, kappa-carrageenan.

\section{Introduction}

Biopolymers like polysaccharides are synthesized from natural sources. Most biopolymer membranes are proton conducting and offer less hazard to the environment. Carrageenan are a group of linear sulfate polysaccharides that are extracted from red edible seaweeds. There are many types of carrageenan and the three main commercial classes of carrageenan are kappa, iota, and lambda. Kappa-carrageenan is well-known with its characteristic which are low cost, easy to purchase and since it is a natural material it therefor renewable [1]. Carrageenan is also non-toxic and sustainable element of biopolymer. It has high proton conductivities at over $100^{\circ} \mathrm{C}$ and under $0{ }^{\circ} \mathrm{C}$, good water uptake above $100^{\circ} \mathrm{C}$ and durable for over 10 years [1]. In this study, kappa-carrageenan is incorporated with ammonium thiocyanate as ionic dopant which acts as a source of proton for the polymer matrix.

\section{Experimental}

Kappa-carrageenan and ammonium thiocyanate $\left(\mathrm{NH}_{4} \mathrm{SCN}\right)$ was purchased from Sigma Aldrich and diluted in $50 \mathrm{ml}$ distilled water in various weight percent (wt. \%). The sample was then stirred for 24 hours to get homogenous solution before being poured into petri dishes for drying process. It was left at room temperature for one day before heat treatment in an oven at $60^{\circ} \mathrm{C}$. The sample was peeled in thin film form and stored in a dessicator before characterization with Fourier Transform Infrared Spectroscopy(FTIR) and Electrical Impedance Spectroscopy(EIS).

\subsection{Electrical Impedance Spectroscopy, EIS}

EIS was conducted using HIOKI 3532-50 LCR Hi-Tester interfaced to a computer for frequencies in the range of $100 \mathrm{~Hz}-1$ MHz. The dried film samples were then placed between sample holders which also act as blocking electrodes, connected to a computer. Cole-Cole plots of imaginary impedance, $Z_{i}$ versus real impedance, $Z_{\mathrm{r}}$ were obtained from the computer and these were used to determine bulk resistances, $\mathrm{R}_{\mathrm{b}}$. The ionic conductivity values were then calculated. using the equation:

$\sigma=\frac{t}{R_{b} A} \mathrm{~S} \mathrm{~cm}^{-1}$

Where $\mathrm{t}$ - thickness of the sample $(\mathrm{cm}), \mathrm{R}_{\mathrm{b}}$ - bulk resistance and $\mathrm{A}$ - the contact area of the electrolyte film.

\subsection{Fourier Transform Infrared, FTIR}

Fourier Transform Infrared Spectroscopy (FTIR) was used to identify the functional group of kappa-carrageenan and ammonium thiocyanate. The method was utilized to identify the intensity of the FTIR spectra based on kappa-carrageenan and ammonium thiocyanate $\left(\mathrm{NH}_{4} \mathrm{SCN}\right)$ interaction.

\section{Results and Discussion}

The dried thin films were characterised and analysed accordingly. 


\subsection{Electrical Impedance Spectroscopy, EIS}

Table 1: Cole - Cole plot of kappa-carrageenan - ammonium thiocyanate at various wt. \%

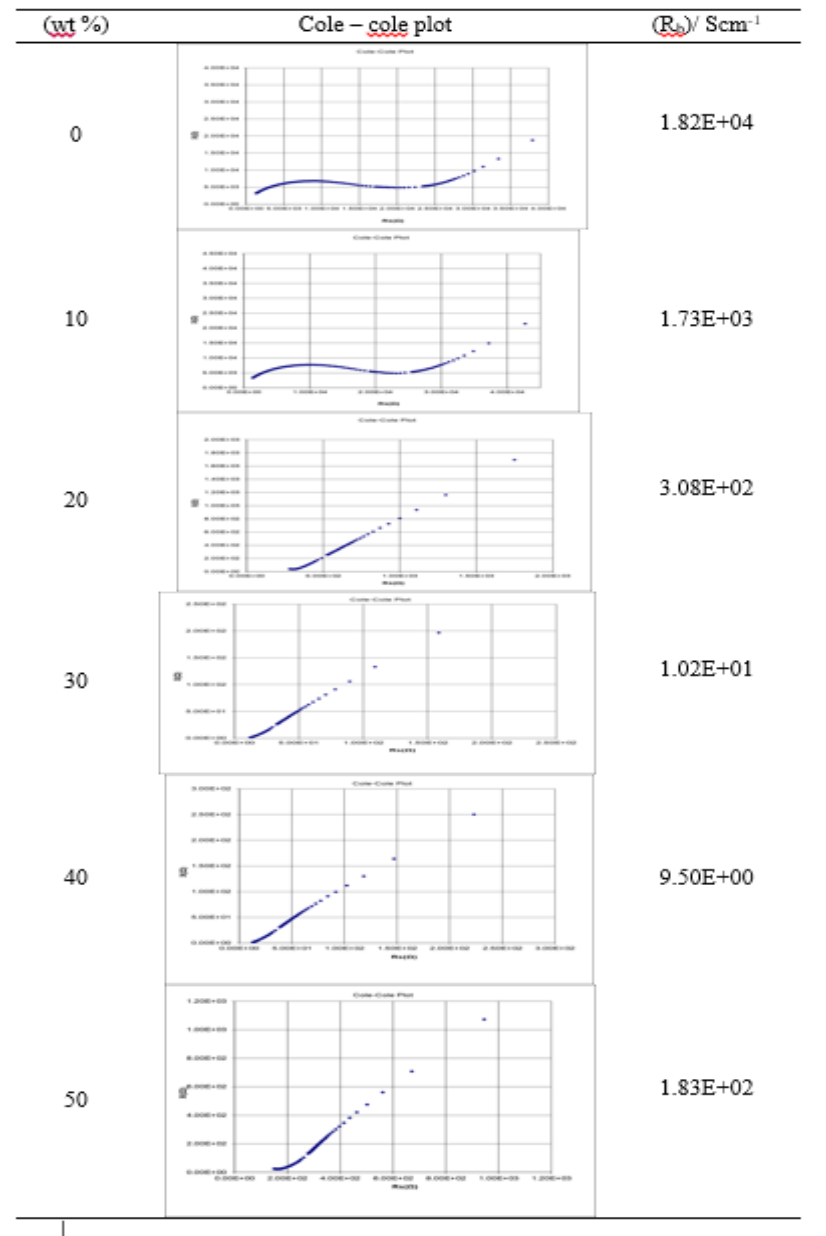

Table 1 shows the graph of $\mathrm{Zi}$ vs. $\mathrm{Zr}$ of different kappacarrageenan - ammonium thiocyanate weight percentage composition (wt. \%). The value of $\mathrm{R}_{\mathrm{b}}$ was obtained from the graph. The conductivity of the sample was calculated using equation (1) and tabulated in Table 2 .

Table 2: Conductivity of kappa-carrageenan - ammonium thiocyanate

\begin{tabular}{cc}
\hline wt.\% $\mathrm{NH}_{4} \mathrm{SCN}$ & Conductivity \\
\hline 0 & $1.36 \mathrm{E}-06 \mathrm{Scm}^{-1}$ \\
10 & $1.71 \mathrm{E}-06 \mathrm{Scm}^{-1}$ \\
20 & $2.46 \mathrm{E}-05 \mathrm{Scm}^{-1}$ \\
30 & $2.61 \mathrm{E}-04 \mathrm{Scm}^{-1}$ \\
40 & $1.64 \mathrm{E}-03$ \\
50 & $2.28 \mathrm{E}-05$ \\
\hline
\end{tabular}

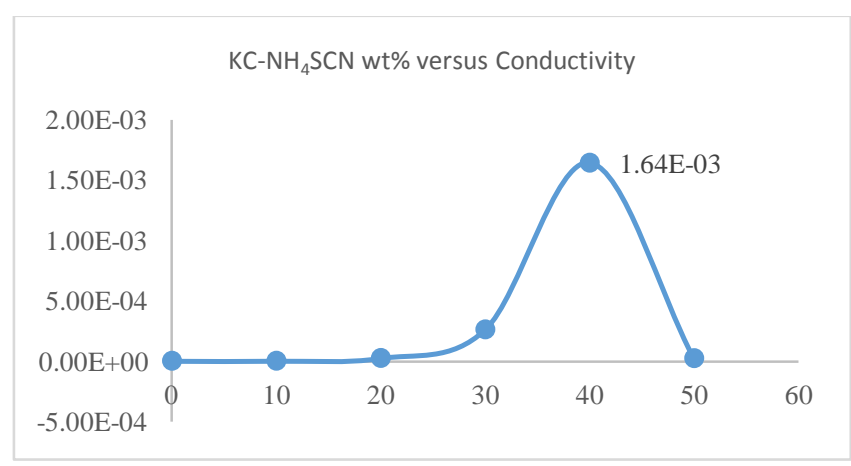

Fig. 1: Conductivity of varied wt. \% $\mathrm{NH}_{4} \mathrm{SCN}$

The conductivity of pure sample of kappa-carrageenan is $1.36 \mathrm{E}-06$ $\mathrm{S} \mathrm{cm}^{-1}$ and increased as the composition of salt increased. As for the samples added with $\mathrm{NH}_{4} \mathrm{SCN}$ at 10 wt. \%, 20 wt. \%, 30 wt. \% and 40 wt. $\%$ the conductivities are $1.71 \mathrm{E}-06 \mathrm{~S} \mathrm{~cm}^{-1}, 2.46 \mathrm{E}-05 \mathrm{~S}$ $\mathrm{cm}^{-1}, 2.61 \mathrm{E}-04 \mathrm{~S} \mathrm{~cm}^{-1}$ and $1.64 \mathrm{E}-03 \mathrm{~S} \mathrm{~cm}^{-1}$ respectively. The highest conductivity was obtained for the sample with 40 wt. \% $\mathrm{NH}_{4} \mathrm{SCN}$, after which the conductivity decreased as shown in Fig. 1.

\subsection{Fourier Transform Infrared Spectroscopy}

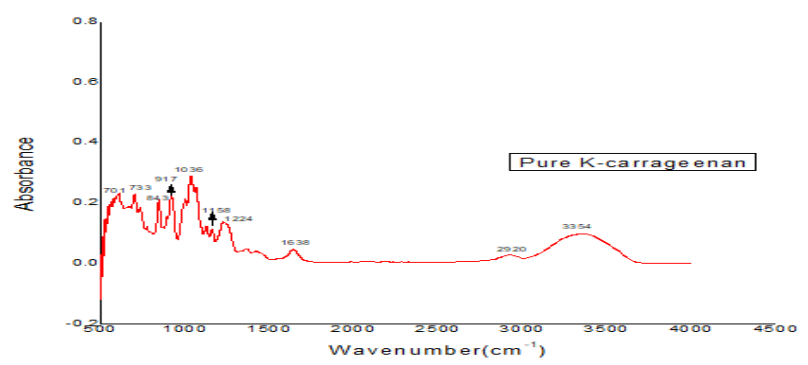

Fig. 2: FTIR spectra of pure K-Carrageenan

Fig. 2 shows the FTIR spectrum of pure kappa-carrageenan. The spectrum indicates that the $\mathrm{C}-\mathrm{H}$ stretching band of pure kappacarrageenan is observed at $2920 \mathrm{~cm}^{-1}$ while C-O stretching is at $1158 \mathrm{~cm}^{-1}$. CN stretching mode peaks at $1622 \mathrm{~cm}^{-1}$. In addition, vibrational modes at $917 \mathrm{~cm}^{-1}$ and $843 \mathrm{~cm}^{-1}$ are attributed to C-S symmetric bending and $\mathrm{SCN}^{-1}$ polar groups respectively.

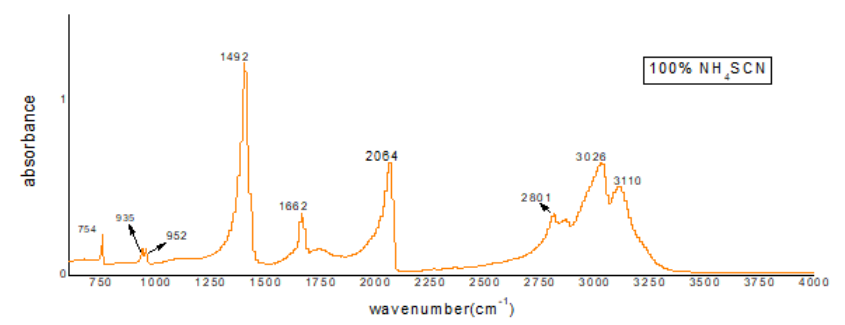

Fig. 3: FTIR spectra of pure $\mathrm{NH}_{4} \mathrm{SCN}$

The FTIR spectra for $100 \%$ pure $\mathrm{NH}_{4} \mathrm{SCN}$ is shown in Fig. 3. At $3110 \mathrm{~cm}^{-1}$ and $2362 \mathrm{~cm}^{-1}$ are peaks attributed to N-H and C-N stretching respectively while the peaks at $1622 \mathrm{~cm}^{-1}$ and $1400 \mathrm{~cm}^{-1}$ belong to $\mathrm{C}$ asymmetric vibration and combined effect of C-S symmetric stretching respectively [2]. The vibrational band at 943 $\mathrm{cm}^{-1}$ and $820 \mathrm{~cm}^{-1}$ are attributed to C-S symmetric bending vibration and $\mathrm{SCN}^{-1}$ polar group. $\mathrm{C}-\mathrm{S}$ symmetric bending band of pure $\mathrm{NH}_{4} \mathrm{SCN}$ is observed at $952 \mathrm{~cm}^{-1}, \mathrm{C}-\mathrm{S}$ symmetric stretching at $1492 \mathrm{~cm}^{-1}, \mathrm{C}$ asymmetric vibration at $1662 \mathrm{~cm}^{-1}$ and $\mathrm{N}-\mathrm{H}$ stretching at $3110 \mathrm{~cm}^{-1}$.

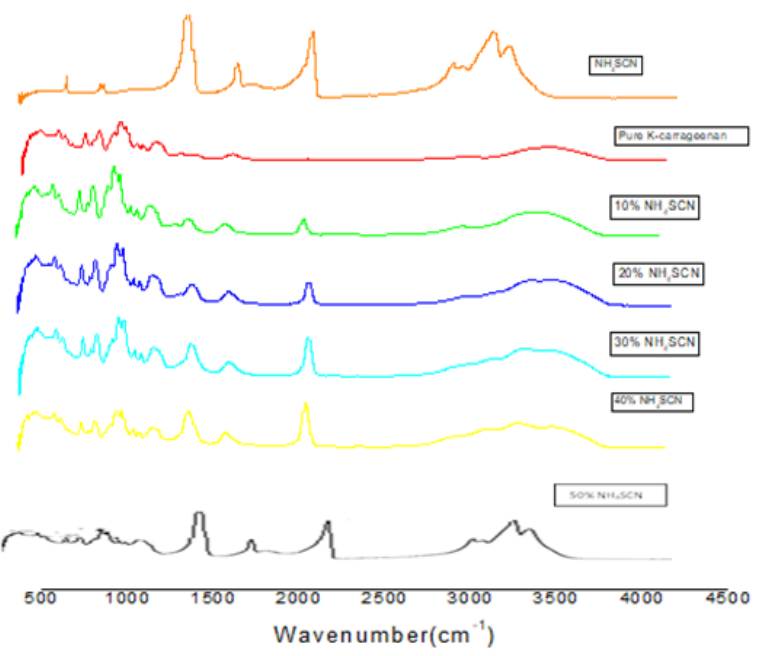

Fig. 4: FTIR spectra for varied wt. \% $\mathrm{NH}_{4} \mathrm{SCN}$ 
Fig 4 depicts the FTIR spectra for the samples with various wt. \% of $\mathrm{NH}_{4} \mathrm{SCN}$. At $1360 \mathrm{~cm}^{-1}$ wavenumber, the intensity increased as the wt. $\%$ of $\mathrm{NH}_{4} \mathrm{SCN}$ increased. Meanwhile the peak at $1638 \mathrm{~cm}^{-1}$ in pure kappa-carrageenan slowly disappeared at 40 wt. \% $\mathrm{NH}_{4} \mathrm{SCN}$ after which the spectra is characterized by the peak attributed to $\mathrm{NH}_{4} \mathrm{SCN}$ at $1600 \mathrm{~cm}^{-1}$ for 50 wt. $\% \mathrm{NH}_{4} \mathrm{SCN}$.

\section{Conclusion}

The highest conductivity obtained at room temperature is $1.64 \mathrm{E}$ $03 \mathrm{~S} \mathrm{~cm}^{-1}$ for the sample with 40 wt. \% $\mathrm{NH}_{4} \mathrm{SCN}$. FTIR studies showed complexation between kappa-carrageenan and $\mathrm{NH}_{4} \mathrm{SCN}$ polymer electrolyte evidenced by the increase in intensity of the peak at $1360 \mathrm{~cm}^{-1}$.

\section{Acknowledgement}

Authors would like to thank Faculty of Applied Sciences and Institute of Science, University Teknologi MARA for funding this research and space.

\section{References}

[1] Rikukawa, M., \& Sanui, K. (2000). "Proton-conducting polymer electrolyte membranes based on hydrocarbon polymers". Progress in Polymer Science (Oxford), 25(10), 1463-1502.

[2] Ikmar, M., Mohamad, N., Universiti, I., Study, F., Ionic, O. N., Of, T., Mohamad, N. (2015). "Proton Conducting Biopolymer Electrolytes Based on Tapioca Starch", Solid State and Technology (April).

[3] Mobarak, N. N., Jumaah, F. N., Ghani, M. A., Abdullah, M. P., \& Ahmad, A. (2015). "Carboxymethyl Carrageenan Based Biopolymer Electrolytes". Electrochimica Acta, 175, 224-231. https://doi.org/10.1016/j.electacta.2015.02.200 